\title{
An Analysis of Surveys on Domestic Violence by Japan's Cabinet Office (1999-2017)
}

\author{
Tomoko Suga \\ Education Center, Rakuno Gakuen University, Hokkaido, Japan \\ Email: tsuga@rakuno.ac.jp
}

How to cite this paper: Suga, T. (2018) An Analysis of Surveys on Domestic Violence by Japan's Cabinet Office (1999-2017). Open Journal of Social Sciences, 6, 56-66. https://doi.org/10.4236/jss.2018.67005

Received: June 18, 2018

Accepted: July 13, 2018

Published: July 16, 2018

Copyright $\odot 2018$ by author and Scientific Research Publishing Inc. This work is licensed under the Creative Commons Attribution International License (CC BY 4.0).

http://creativecommons.org/licenses/by/4.0/

\section{(c) (i) Open Access}

\begin{abstract}
Japan's Cabinet Office conducted surveys on DV seven times (1999, 2002, $2005,2008,2011,2014,2017)$. As a secondary source, we used the data on the Cabinet Offices website. In 2001, the first DV law, the Act on the Prevention of Spousal Violence was passed, after which the Japanese public began to recognize DV. Based on the question item on "domestic violence from a spouse" the data of the Cabinet Office's survey from 2005 to 2017 indicated that on average, just over $30 \%$ of women experienced DV, while just under $20 \%$ of men did. These figures have not changed much. The proportions of victims who use advisory services have increased with every survey due to political movements and Japanese policy. In 2017, the data showed that a little less than $58 \%$ of women and almost $27 \%$ of men used advisory services. The most recent survey conducted in 2017, showed that people who do not separate from their spouse experience DV. In terms of the reasons that they do not separate, "children" weighed high on the list.
\end{abstract}

\section{Keywords}

Domestic Violence, Japan, Cabinet Office, Survey

\section{Introduction}

In consideration of respect for individuals and equality under the law, which are expressly stipulated in the Japanese Constitution, progress has been made in Japan through efforts to protect human rights and realize genuine equality between women and men. Nevertheless, although domestic violence (DV) constitutes a serious violation of human rights, as well as being a crime, attempts to efforts to relieve victims have not always been adequate in all instances [1]. Given that the Diet passed the Act on the Prevention of Spousal Violence in April 2001, the history of DV measures in Japan is relatively brief. In 1992, a pri- 
vate-sector women's group conducted the first nation-wide fact-finding survey into spousal and intimate partner abuse. The results led the Prime Minister's Office (now the Cabinet Office) to carry out the first of a series of surveys on DV starting in 1999 [2]. The surveys are conducted triennially, with seven so far (1999, 2002, 2005, 2008, 2011, 2014, and 2017). In this article, we summarize the trends seen in the findings. Now that nearly twenty years have passed since the first surveys, it is essential to share the data on DV in Japan with the wider world.

The 1999 survey had a significant impact, prompting the government to propose the Act on the Prevention of Spousal Violence, which the Diet passed in April 2001. At the time, only physical violence was defined as DV, and a stay-away order would only be available for the victim. Similarly, a protection order could only be applied to a spouse. Moreover, the perpetrator could only be prevented from returning to a residence for up to two weeks.

In December 2004, the Act on the Prevention of Spousal Violence was amended for the first time. The definition of DV was broadened to include psychological and sexual abuse, and stay-away orders were made available for the victim's children as well as the victim him/herself. The amendment also extended the scope of protection orders to include a former spouse or cohabiting partner. The perpetrator could now be prevented from returning to a residence for up to two months and prohibited from loitering around the residence.

A second amendment was approved in January 2008 which imposed a duty on municipal authorities to make efforts in setting up DV shelters. The scope of stay-away orders was further expanded; perpetrators could now be forbidden from approaching, children or kin living with the victim (in addition to the victim him/herself), and could also be barred from phoning such persons.

The third amendment was passed in January 2014. Protection orders would now apply to intimate partners who were economically linked as well as spouses, former spouses, and cohabitating partners [3]. Taiwan enacted a DV law in 1998, which in addition to spousal violence, covered violence against children the elderly, and family members in general [4]. By comparison, Japan's DV legislation had many shortcomings. The legislation was amended three times in large part due to the Cabinet Office's triennial survey on DV. In this study, we look at the change to "domestic violence from a spouse", "physical violence", "psychological violence", "sexual violence", "the proportions of victims who use advisory service", “women's actions after suffering domestic violence", and “men's actions after suffering domestic violence". Hereunder, we examine how DV patterns in Japan have changed over time to derive hints for how to tackle the problem.

\section{Methodology}

\subsection{Procedures}

As a secondary source, we used public accessible data from the seven DV surveys 
published on the website of the Cabinet Office's Gender Equality Bureau [5].

1) December 1999: 4500 men and women aged 20 or above were randomly selected. Questionnaire surveys were posted to these individuals, and the completed questionnaires were returned. Effective response rate: $\mathrm{n}=3405$ (75.7\%) women $=1773$, men $=1632[6]$

2) December 20024500 men and women aged 20 or above were randomly selected. Questionnaire surveys were posted to these individuals, and the completed questionnaires were returned. Effective response rate: $\mathrm{n}=3322(73.8 \%)$ women $=1802$, men $=1520[7]$

3) December 20055000 men and women aged 20 or above were randomly selected. Questionnaire surveys were posted to these individuals, and the completed questionnaires were returned. Effective response rate: $\mathrm{n}=2888$ (64.2\%) women $=1578$, men $=1310$

Married or have married in the past: women $=1283$, men $=1045[8]$

4) December 20085000 men and women aged 20 or above were randomly selected. Questionnaire surveys were posted to these individuals, and the completed questionnaires were returned. Effective response rate: $\mathrm{n}=3129(62.6 \%)$ women $=1675$, men $=1454$

Married or have married in the past: women $=1358$, men $=1077$ [9]

5) December 20115,000 men and women aged 20 or above were randomly selected. Questionnaire surveys were posted to these individuals, and the completed questionnaires were returned. Effective response rate: $\mathrm{n}=3293$ (65.9\%) women $=1751$, men $=1542$

Married or have married in the past: women $=1403$, men $=1195[10]$

6) December 20145000 men and women aged 20 or above were randomly selected. Questionnaire surveys were posted to these individuals, and the completed questionnaires were returned. Effective response rate: $\mathrm{n}=3544$ (70.9\%) women $=1811$, men $=1733$

Married or have married in the past: women $=1401$, men $=1272[11]$

7) December 20175000 men and women aged 20 or above were randomly selected. Questionnaire surveys were posted to these individuals, and the completed questionnaires were returned. Effective response rate: $\mathrm{n}=3376(67.5 \%)$ women $=1807$, men $=1569$

Married or have married in the past: women $=1366$, men $=1119[12]$

\subsection{Contents of the Questionnaire}

Of the question items on the seven DV surveys, we selected those that appeared in all seven. From among the question items, we selected nine important ones: 1) the rate of DV victims; 2) the rate of physical violence; 3) the rate of psychological violence; 4 ) the rate of sexual violence; 5) the rate of DV who received advisory services, 6) reasons for not using advisory services; 7) actions of female DV victims; 8) actions of male DV victims; and 9) reasons why DV victims do not leave the perpetrator. Since the question format in the 1999 survey differs from 
that of the surveys from 2002 and onward, we cannot show the results in a graph. Therefore, we have only presented the descriptive data.

\section{Result}

\subsection{Domestic Violence from a Spouse}

Figure 1 shows the results for the question item "domestic violence from a spouse". Since this item was not included in the 1999 and 2002 surveys, the figure pertains to the data from 2005 onward. Regarding the outcomes for women in $2005,33.2 \%$ experienced DV by a spouse; that figure was, $33.2 \%$ in 2008 , $32.9 \%$ in $2011,23.7 \%$ in 2014 , and $31.3 \%$ in 2017 , respectively. The rate dipped in 2014 , but this was only temporary. As for men, the rate has not significantly differed since 2005 , as $17.4 \%$ experienced spousal violence in $2005,17.7 \%$ in $2008,18.3 \%$ in $2011,16.6 \%$ in 2014 , and $19.9 \%$ in 2017 , respectively.

\subsection{Physical Violence}

Figure 2 shows the outcomes for the question item "physical violence". In terms

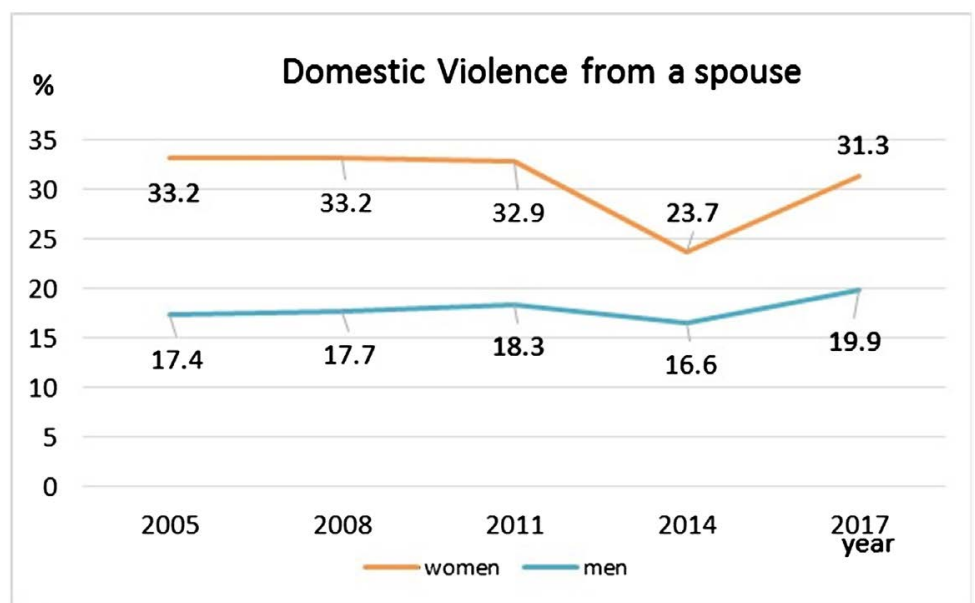

Figure 1. Domestic violence from a spouse.

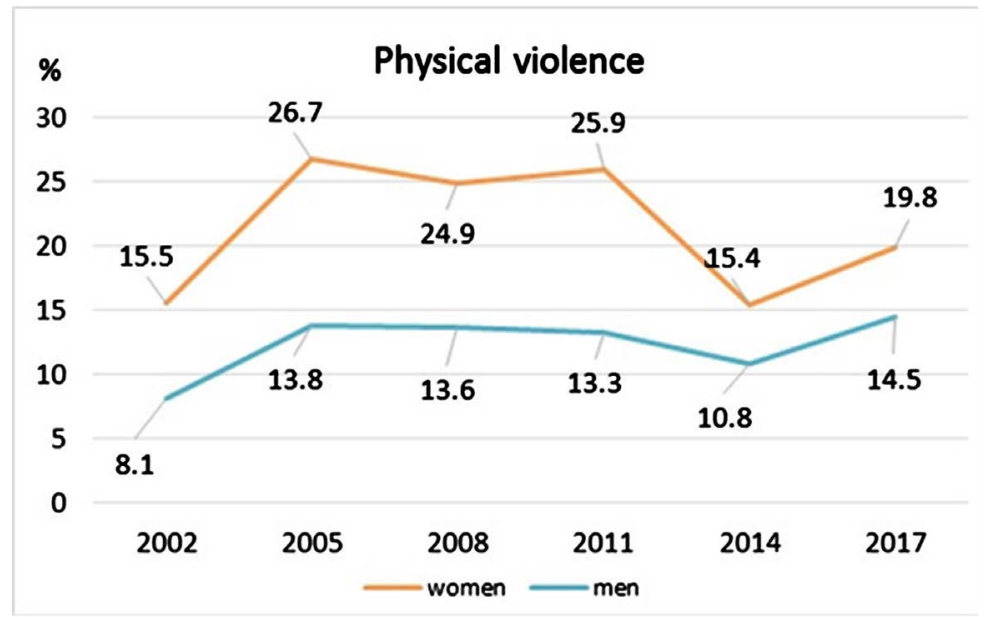

Figure 2. Physical violence. 
of the findings for women, $15.5 \%$ experienced physical violence from their spouse in $2002,26.7 \%$ in $2005,24.9 \%$ in 2008 , and $25.9 \%$ in 2011 , respectively. The rate decreased to $15.4 \%$ in 2014 , and rose to $19.8 \%$ in 2017 . As for men, $8.1 \%$ experienced physical violence in $2002,13.8 \%$ in $2005,13.6 \%$ in $2008,13.3 \%$ in 2011 , and $10.8 \%$ in 2014. In 2017, $14.5 \%$ of men experienced DV, indicating a rising trend.

\subsection{Psychological Violence}

Figure 3 shows the outcomes for the question item "psychological violence". Regarding the results for women, 5.6\% experienced psychological violence from their spouse in $2002,16.1 \%$ in $2005,16.6 \%$ in $2008,17.8 \%$ in $2011,11.9 \%$ in 2014 , and $16.8 \%$ in 2017 , respectively. Among men, $1.8 \%$ experienced psychological violence in 2002 , but this figure rose to $8.1 \%$ in $2005,8.8 \%$ in $2008,9.5 \%$ in $2011,9.1 \%$ in 2014 , and $10.0 \%$ in 2017 , respectively. The rate of male DV victims is clearly rising.

\subsection{Sexual Violence}

Figure 4 shows the results for the question item "sexual violence". In terms of

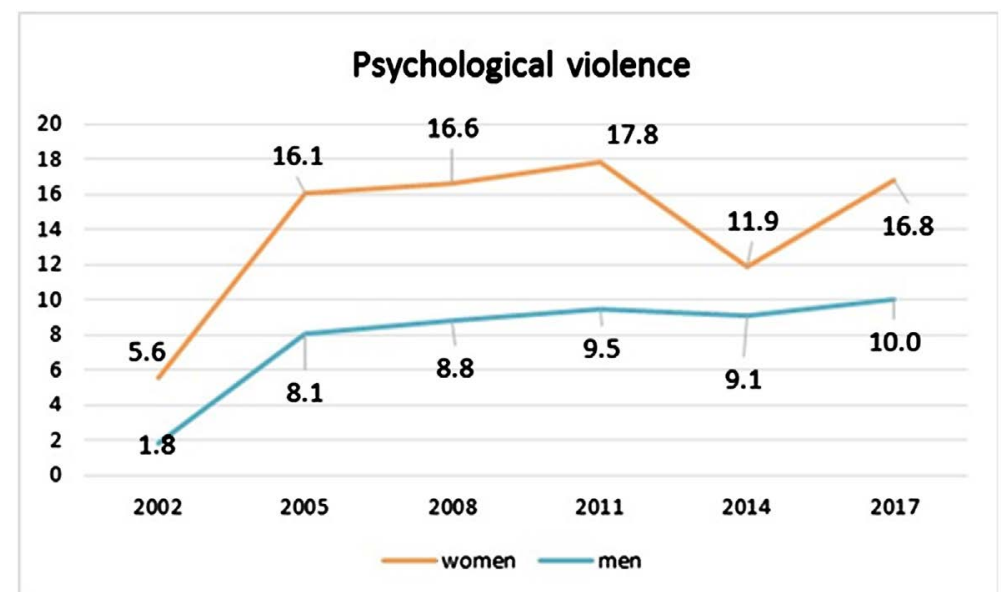

Figure 3. Psychological violence.

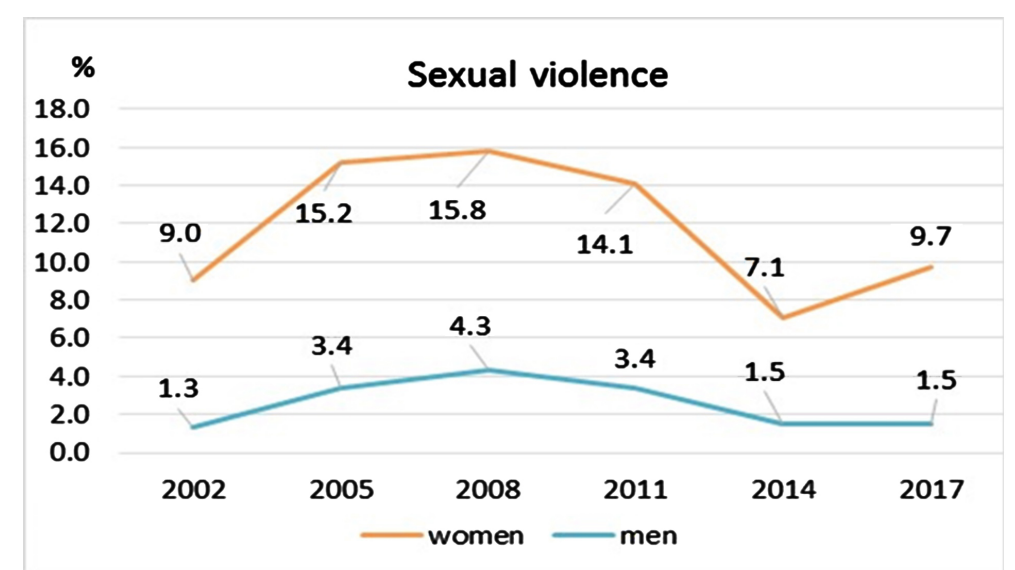

Figure 4. Sexual violence. 
the results for women, $9.0 \%$ experienced sexual violence from their spouse in $2002,15.2 \%$ in $2005,15.8 \%$ in $2008,14.1 \%$ in $2011,7.1 \%$ in 2014 , and $9.7 \%$ in 2017, respectively. Among men, 1.3\% underwent sexual violence in 2002, 3.4\% in $2005,4.3 \%$ in $2008,3.4 \%$ in $2011,1.5 \%$ in 2014 , and $1.5 \%$ in 2017 , respectively. While the figures for men are low, they are consistently present.

\subsection{The Proportion of Victims Who Use Advisory Services}

Figure 5 shows the trends in using DV advisory services. Looking first at the outcomes for women, $48.0 \%$ used advisory services in 2005, $45.9 \%$ in 2008 , $55.0 \%$ in $2011,50.3 \%$ in 2014 , and $57.6 \%$ in 2017 , respectively. As for men, $15.6 \%$ used advisory services in $2005,21.7 \%$ in $2008,19.3 \%$ in $2011,16.6 \%$ in 2014 , and $26.9 \%$ in 2017 , respectively. Usage rates are rising for both men and women.

\subsection{Reasons for Not Using Advisory Services}

We analyzed multiple answer options for the question of why a person did not use advisory services after suffering violence. In 1999, 41.2\% of women had thoughts such as "If I can put up with this, we might be able to carry on the way things are" or "I'm partly to blame". As for men, 48.1\% answered "It was not serious enough to warrant seeking help" [6]. In 2002, 52.9\% of women and $66.7 \%$ of men said "It was not serious enough to warrant seeking help", while $50.0 \%$ of women and $55.6 \%$ of men answered "I thought there would be little point in seeking help" [7].

In $2005,45.2 \%$ of women and $69.7 \%$ of men answered "It was not serious enough to warrant seeking help", while $39.3 \%$ of women and $44.7 \%$ of men replied, "I'm partly to blame" [8]. In $2008,50.0 \%$ of women and $67.6 \%$ of men answered, "It was not serious enough to warrant seeking help", while $35.7 \%$ of women and $43.7 \%$ of men stated, "I'm partly to blame" [9]. In 2011, 50.0\% of women and $76.1 \%$ of men said, "It was not serious enough to warrant seeking

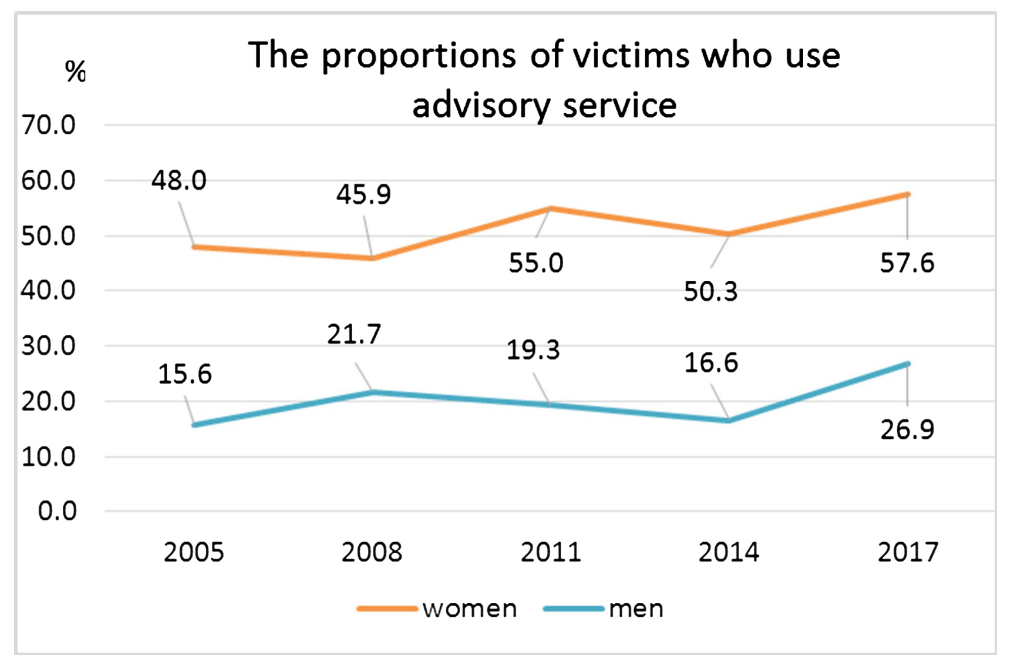

Figure 5. The proportion of victims who use advisory service. 
help", while $34.3 \%$ of women and $44.8 \%$ of men reported, "I'm partly to blame" [10].

In $2014,47.0 \%$ of women and $64.2 \%$ of men claimed, "It was not serious enough to warrant seeking help", while $32.2 \%$ of women and $33.3 \%$ of men answered "I'm partly to blame" [11].

In $2017,54.6 \%$ of women and $61.9 \%$ of men stated, "It was not serious enough to warrant seeking help", while $33.7 \%$ of women and $34.8 \%$ of men answered, "I’m partly to blame" [12].

\subsection{Women's Actions after Suffering Domestic Violence}

In $2005,4.7 \%$ of women reported that they left the perpetrator. The rate has steadily risen since then, reaching $12.6 \%$ in 2017 . The proportion of women who reported that they did not separate from the perpetrator despite wanting to has remained largely the same, trending between $42.1 \%$ and $49.1 \%$. The ratio of women who wanted to stay with the perpetrator was $42.4 \%$ in 2008 , but had fallen to $26.7 \%$ by 2017 (Figure 6).

\subsection{Men's Actions after Suffering Domestic Violence}

In $2005,1.5 \%$ of men reported that they left the perpetrator. The rate has increased steadily since then, reaching $7.2 \%$ in 2017 . The proportion of men who stated that they did not separate from their perpetrator despite wanting to was $21.4 \%$ in $2005,17.8 \%$ in $2008,27.4 \%$ in $2011,28.9 \%$ in 2014 , and $21.5 \%$ in 2017. The rate of men who wanted to remain with their perpetrator was $60.4 \%$ in 2005 , but had fallen to $46.2 \%$ by 2017 (Figure 7).

\subsection{Reasons for Not Separating from Spouse}

On multiple question items, we asked the respondents about their reasons for

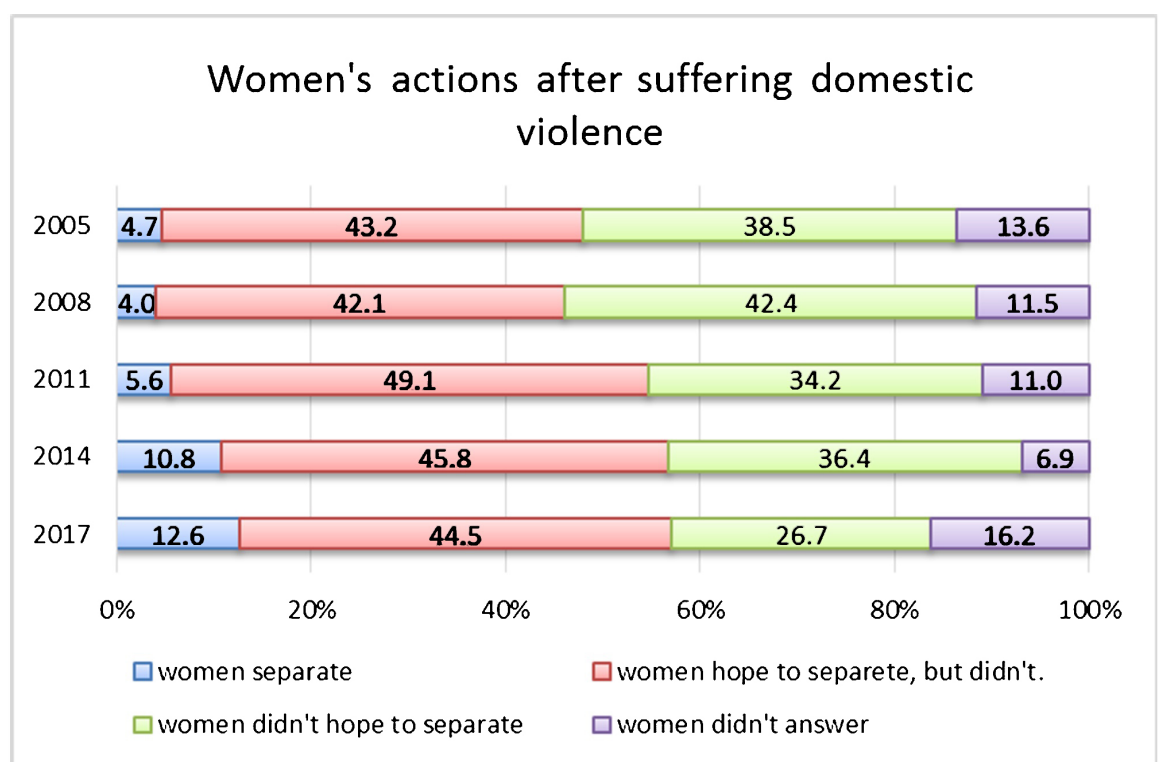

Figure 6. Women's actions after suffering domestic violence. 


\section{Men's actions after suffering domestic violence}

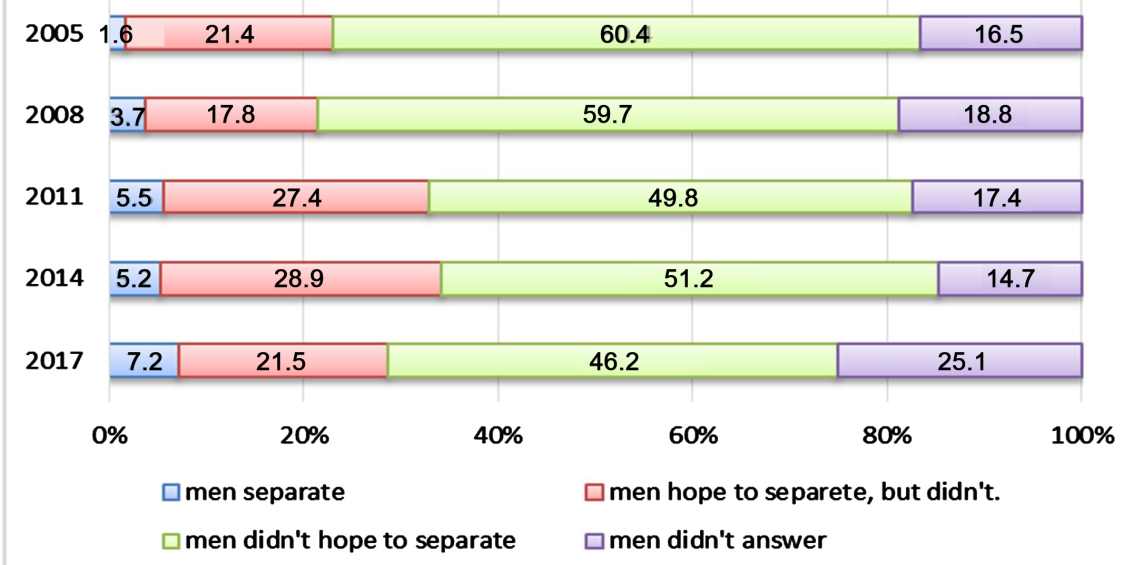

Figure 7. Men's actions after suffering domestic violence.

not wanting to separate from a violent spouse. In 2005, 27.7\% of women and $23.1 \%$ of men cited "worries about financial issues", while $15.8 \%$ of women and $17.9 \%$ of men said "I believed that my spouse would not inflict further violence" [8]. In 2008, $28.4 \%$ of women pointed to concerns about financial issues, while $14.2 \%$ claimed that their spouse would not inflict further violence. In the same year, $32.4 \%$ of men expressed their desire to "keep up appearances", while $20.6 \%$ said, "I thought that my spouse couldn't manage without me" [9]. In 2011, $57.3 \%$ of women and $65.0 \%$ of men said "because of my child/children" while $18.9 \%$ of women and $5.0 \%$ of men mentioned worries about financial matters [10]. In 2014, $65.8 \%$ of women and $59.0 \%$ of men cited their child/children, $44.7 \%$ of women pointed to concerns about financial affairs, and $26.2 \%$ of men stated their belief that their spouse would change [11]. In 2017, $66.8 \%$ of women and $60.4 \%$ of men said their child/children, $48.9 \%$ of women expressed worries about financial issues, and $33.2 \%$ of men cited their desire to keep up appearances.

\section{Discussion}

According to the 1999 survey, many women opted to stay with a violent spouse out of a deeply rooted self-abnegating mentality, as indicated by reasons such as "If I can put up with this, we might be able to carry on the way things are" or "I'm partly to blame". The enforcement of the Act on the Prevention of Spousal Violence in 2001 helped establish a broad understanding in Japan of what constitutes domestic violence, prompting victims to break their silence. However, at the time of the 2002 survey, the law still only recognized physical violence to be DV, which probably explains why the figures for psychological and sexual violence are so low in the survey.

At the time of the 2005 survey, the first amendment of the law, in 2004, had broadened the scope of DV to include psychological and sexual violence. Accor- 
dingly, the figures for psychological and sexual violence reflected a sharp rise. These higher rates do not necessarily indicate a surge in the number of DV victims; it is more likely that victims who had not previously recognized themselves as such started speaking out. The amount of men and women suffering spousal violence varied little across the 2005, 2008, and 2011 surveys. The data suggests that around $32 \%$ of women and about $18 \%$ of men experience DV. However, the proportion for female victims was lower in the 2014 survey, which was conducted in December. January of that year saw the fourth amendment to the Act on the Prevention of Spousal Violence, which extended the scope of protection orders to include economically linked intimate partners [3]. The policy of targeting violence at the stage of dating in relationships may have led to a reduction in the overall number of women experiencing DV. Another factor is that Japan made progress in matters concerning DV between December 2011 and December 2014. In March 2012, Japan established an emergency hotline offering one-stop support for DV victims. In June 2012, Tokyo established violence rescue shelters, and in June 2013, the country strengthened its anti-stalker law [2].

In the 2017 survey, the proportion of female DV victims increased to a little over $30 \%$. Likewise, victim rates among men indicate a rising trend. The fact that 2017 saw record numbers of male and female victims using advisory services indicates that social policies have gained traction. However, the answer rates for "I thought there would be little point in seeking help" remain high-just shy of $50 \%$ for women and around $65 \%$ for men-which suggests that more needs to be done to raise public awareness. While the number of victims who opt to separate from their perpetrator continues to rise, the percentage remains at about the $10 \%$ mark; it is necessary to find ways to change this trend. Looking at the free descriptive responses regarding why the victim did not separate from their spouses, "worries about financial issues" was the most common motive among men and women before 2008; since 2011, "child/children" has been the top reason. According to a recent study, children who witness DV between their parents have $6.1 \%$ less occipital lobe volume compared to other children [13]. The public needs to be better informed about the negative consequences of staying married to a violent spouse for the sake of one's children.

Another point to note is that the problem of DV is not solved by divorce alone. A Japanese study has highlighted how much energy victims need to rehabilitate themselves psychologically [14]. How then can we reduce the numbers of DV victims? In a US study, a prevention program targeting young people was effective [15]. Likewise, a Japanese prevention program targeting high school students was effective for instilling awareness of DV [16]. Such programs is also promote understanding of relationships [17]. A 2011 US study reported that 9.4\% of 12-year old boys and 9.2\% of 12-year old girls had already experienced physical violence from a dating partner [18]. As for the Japanese research in this area, a 2017 study examined dating violence among people aged 18 or older and reported that $21.4 \%$ of women and $11.5 \%$ of men had experienced such violence 
[12]. Thus, an effective strategy to reduce DV would be to focus on preventing dating/intimate partner violence among young people, in addition to spousal violence.

In this study, we found that physical violence continues in high proportions, and according to recent data from 2017, only half of the women and one quarter of the men who experienced DV used an advisory service. We need to cultivate prevention and help for them. In addition, we need to obtain information on foreign countries' DV policies to prevent Japanese people from experiencing DV.

\section{Conclusions}

Japan's Cabinet Office conducted surveys on DV seven times (1999, 2002, 2005, 2008, 2011, 2014, 2017), as a secondary source, we used the data on the Cabinet Offices website. In Japan, the Diet passed the Act on the Prevention of Spousal Violence in April 2001. Before this, the 1999 survey revealed that $41.2 \%$ of women who suffered from violence had thoughts such as. "If I can put up with this, we might be able to carry on the way things are". The question item on "domestic violence from a spouse" began in the 2005 survey, and from 2005 to 2017 , just over $30 \%$ of women suffered violence, while that figure was a little less than $20 \%$ for men. In 2005 , for the question item on "the proportion of victims who use advisory services" this figure was just under $50 \%$ for women and nearly $27 \%$ for men. This may be due to political movements and Japanese policy.

As of 2017 , nearly $27 \%$ of men and almost $46 \%$ of men still do not wish to separate from their partners, even though they suffer from violence. The reason why they do not hope to separate is "for children". In the future, we must cultivate an awareness of the negative effects of parental violence on children.

\section{Acknowledgements}

This research was conducted with the supported of JSPS KAKENHI Grant Number JP18K18294.

\section{References}

[1] Gender Equality Bureau Cabinet Office (2001) Act on the Prevention of Spousal Violence and the Protection of Victims, Act No.31 of 2001, 1. http://www.gender.go.jp

[2] Ogawa, M. (2015) Domestic Violence and Women's Shelter. For the Support of Victim. Seori Syobou in Japan, 354-356.

[3] Suga, T. (2015) Domestic Violence Prevention Education for Junior High School Students. Kazama Syobou in Japan, 8-10.

[4] Kitanaka, C., Inoue, M., Kiyosue, A., Mtsumura, U. and Ri, K. (2016) The Problem of the DV Victim Support of Taiwan and Malaysia. Asian Women's Research, 25, 37-55.

[5] The Cabinet Office's Gender Equality Bureau. http://www.gender.go.jp/research/index.html

[6] Gender Equality Bureau Prime Minister's Office (1999) Survey on Domestic Vi- 
olence.

[7] Gender Equality Bureau Cabinet Office (2002) Survey on Domestic Violence.

[8] Gender Equality Bureau Cabinet Office (2005) Survey on Domestic Violence.

[9] Gender Equality Bureau Cabinet Office (2008) Survey on Domestic Violence.

[10] Gender Equality Bureau Cabinet Office (2011) Survey on Domestic Violence.

[11] Gender Equality Bureau Cabinet Office (2014) Survey on Domestic Violence.

[12] Gender Equality Bureau Cabinet Office (2017) Survey on Domestic Violence.

[13] Tomoda, A., Polcari, A., Anderson, C.M. and Teicher, M.H. (2012) Reduced Visual Cor tex Gray Matter Volume and Thickness in Young Adults Who Witnessed Domestic Violence during Childhood. PLOS One, 7, e52528.

https://doi.org/10.1371/journal.pone.0052528

[14] Masui, K. (2017) Models of Recovery and Giving Meaning to Experiences of Domestic Violence: An analysis of Post-Traumatic Growth of Survivors of Domestic Violence. Japanese Journal of Social Welfare, 58, 55-66.

[15] Foshee, V.A., Benefield, T., Dixon, K.S., Chang, V.S., Ennett, S.T., Moracco, K.E. and Bowling, J.M. (2015) The Effects of Moms and Teens for Safe Date: A Dating Abuse Prevention Program for Adolescents Exposed to Domestic Violence. Journal of Youth and Adolescence, 44, 995-1010. https://doi.org/10.1007/s10964-015-0272-6

[16] Suga, T. and Shiota, M. (2018) The Effectiveness of Preventive Education against Dating Violence in Japanese Agricultural and Commercial High Schools. Open Access Library Journal, 5, e4542. https://doi.org/10.4236/oalib.1104542

[17] Suga, T. (2017) Results of Dating Violence Prevention Education for Japanese High School Boys. Open Journal of Social Sciences, 5, 173-185. https://doi.org/10.4236/jss.2017.512013

[18] Rothman, E.F. and Xuan, Z. (2014) Trends in Physical Dating Violence Victimization among U.S. High School Students, 1999-2011. Journal of School Violence, 13, 277-290. https://doi.org/10.1080/15388220.2013.847377 